\title{
Two Social Protection Programs in Pakistan
}

\section{Ijaz Nabi*}

\begin{abstract}
Pakistan has launched two far reaching social protection programs. The federal government's Benazir Income Support Program has, at its core, an unconditional cash grant for the poorest households. Responding to the concern that this runs the risk of creating a large pool of permanent government handout recipients, the federal government has also launched an ambitious skills development program. At the provincial level, the government of Punjab is implementing skills development as social welfare in the four poorest Southern Punjab districts. The paper discusses the structure of the two programs, their success at reaching the poor and the monitoring challenges to assess their overall effectiveness.
\end{abstract}

Keywords: Social protection, targeted transfer program, skills development, Pakistan.

JEL classification: R58, 020.

\section{Introduction}

Social protection in Pakistan went through a remarkable change with the return of democracy in 2008. In a short period, the newly elected federal government of the Pakistan People's Party (PPP) and the main opposition government of the Pakistan Muslim League (Nawaz) (PML-N) in Punjab had inherited an economy in tatters. Pakistan's chronic economic ills, the fiscal deficit, and the associated balance of payments crisis that had begun to surface in 2006 but had been restrained with "band aid," surfaced with a vengeance amid the political uncertainty of 2007. To avoid a major economic crisis, the elected PPP government was forced to curtail public expenditure sharply and devalue the rupee.

Given the economic slowdown, poor job creation, and rampant inflation, the impact of macroeconomic adjustment on the poor was predictably harsh. The Benazir Income Support Program (BISP), a federal

\footnotetext{
* Country Director, International Growth Center, Pakistan, and Visiting Faculty, Department of Economics, Lahore University of Management Sciences, Pakistan.
} 
program created by a parliamentary act in 2010, has at its core an unconditional cash transfer program targeting the poorest 20 percent of the population, and was designed to cushion the impact of economic hardship on the poor and the most vulnerable.

The PML-N government in Punjab took a different approach to social protection. Soon after taking office, the provincial government put in place a program subsidizing bread. Called Sasti Roti (literally, cheap bread), untargeted subsidized rotis were made available at 12,000 tandoors (bakeries) throughout urban Punjab.

The federal BISP and Punjab's Sasti Roti programs represented a sevenfold increase in expenditure on social protection (Gazdar, 2011) (see Figure 1). Within the first year of its establishment, the BISP was reaching more beneficiaries than the two previous social protection programs, Baitul-Maal and zakat (Table 1); by the third year, 2010/11, it was reaching over 3 million beneficiaries. The program's design and scope are discussed in Section 2.

Figure 1: Social protection expenditure as a share of total expenditure

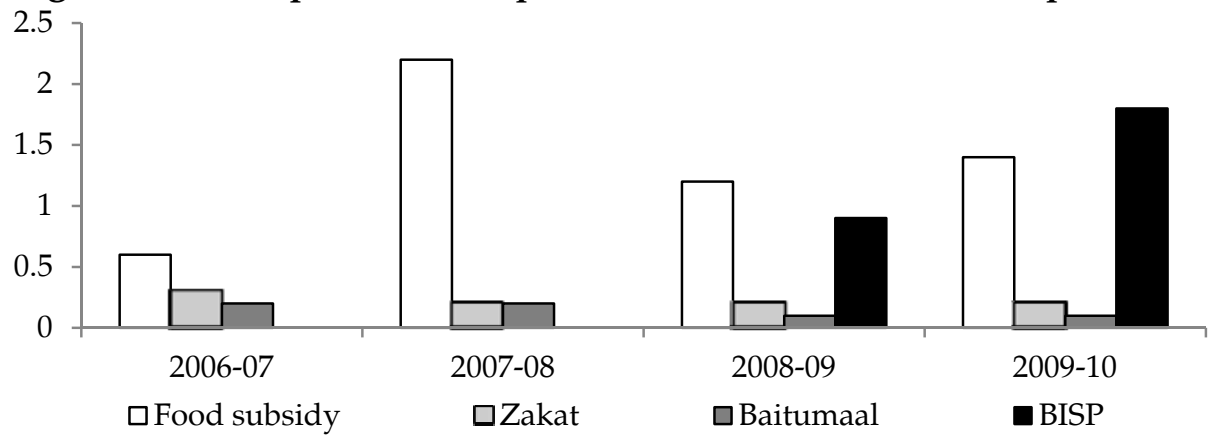

Source: Gazdar (2011) and Pakistan, Ministry of Finance (2011).

Table 1: Beneficiaries of the main social protection programs

\begin{tabular}{lrcc}
\hline & \multicolumn{3}{c}{ Number of beneficiaries } \\
\cline { 2 - 4 } Program & $\mathbf{2 0 0 8 / 0 9}$ & $\mathbf{2 0 0 9 / 1 0}$ & $\mathbf{2 0 1 0 / 1 1}$ \\
\hline Pakistan Bait-ul-Maal & 159,822 & $1,915,071$ & $1,885,035$ \\
Zakat & $1,085,378$ & $1,289,050$ & $1,109,151$ \\
BISP & $1,760,000$ & $2,290,000$ & $3,081,000$ \\
\hline
\end{tabular}

Source: Gazdar (2011). 
Even though social protection was scaled up in response to the economic crisis of $2007 / 08$, the vulnerability of low-income groups to hardship is endemic. This is evident in the pattern of poverty incidence in Pakistan whereby a large number of income earners lie in a band just above and below the poverty line (estimated in 2011/12 at PRs 2,243 per capita per month) (Shaikh, 2013). Economic downturn and inflation are just one cause of vulnerability. Others are agriculture cycles, natural disasters (earthquakes, floods), and illness of the main family earner.

Mindful of the vulnerability that exposes the poor-and especially its youth-to prolonged periods of unemployment and low-income earnings, and responding to social dislike of permanent handouts, both the federal government's BISP (through its Waseela-e-Rozgar program) and the Punjab government have implemented skills development programs as alternative forms of social protection, ones with an in-built exit strategy. The Punjab Skills Development Fund (PSDF), which focuses on the province's four southern districts that are marked by pronounced elements of vulnerability, is the more interesting of the two in terms of design and is discussed in Section 3. Section 4 concludes with some comments on issues going forward, including the all-important issue of fiscal sustainability surrounding the two programs.

\section{BISP}

The BISP was launched in 2008 in a nightmarish economic scenario. The economy was collapsing under the burden of rapidly rising energy and food prices, a gaping fiscal deficit, and soaring inflation. It was clear that the poor would be the worst affected and without some income support, risked losing whatever gains they had made in the previous growth spurt.

The BISP's immediate objective was to cushion the negative effects of slow economic growth, the food crisis, and inflation on the poor, particularly women, through the provision of cash transfers of PKR 1,000 (approximately USD12) per month to eligible families. As one of the world's largest such programs, it would eventually provide income support to 7 million households (20 percent of the poorest people in a population of 180 million). It has since evolved into the country's main social safety net.

Rolling out an income support program that minimizes leakages and reaches the intended population in a country the size and diversity of Pakistan was not easy. It took a couple of years of intense engagement with 
the world's best technical experts and resolute commitment by the Pakistani management to get things right.

The period from 2008/09 to 2011/12 was one of rapid learning for the BISP. Best practices from around the world were tailored to the Pakistani environment to develop a modern and efficient social protection system. The innovations included (i) switching from community-based targeting to more scientific targeting, (ii) developing one of the largest databases of poor households, (iii) instituting automated payment generation, (iv) providing cash transfers through innovative technology, (v) establishing an automated case management system that interfaced with beneficiaries at the tehsil level, and (vi) using third-party evaluations of processes and the program to assess its efficiency and improve the quality of services.

The core program providing cash support of PKR 1,000 per month per beneficiary household reached 4 million families in 2011/12. This helped fill 60 percent of the gap between the actual income of poor households and the income needed to climb out of poverty. The bulk of the funds for the cash program are drawn from the government's own budgetary resources. The two conditions for eligibility are that (i) the household belongs to the poorest 20 percent of the population, and (ii) the recipient is a female household member who may be currently married, divorced, or widowed. Empowering poor women is thus a central pillar of the program.

In addition to the core unconditional cash program, and using the same database, the BISP has launched a major conditional cash program, Waseela-e-Taleem, to help increase enrolment in primary schools. Other programs are Waseela-e-Rozgar (skills training), Waseela-e-Haq (entrepreneurship development), and Waseela-e-Sehat (health). This paper discusses the core cash program and Waseela-e-Taleem, the two flagship programs of the BISP.

Since October 2011, the BISP has delivered these programs under the watchful eye of an independent board of directors. There are 11 board members (five independent members, five government representatives, and one secretary/chief executive officer [CEO]). Prominent members who have driven board proceedings include a former governor of the State Bank of Pakistan, a former finance minister, a prominent educationist and former minister, a well-known publisher/journalist, and myself, a former dean of the Lahore University of Management Sciences. The board and its four committees have held 14 meetings since October 2011 scrutinizing BISP hiring policies, program design, finances, and operations. Third-party 
internationally procured evaluations are given a large weight in this scrutiny and are discussed below.

\subsection{Unconditional Cash Grant Program}

The number of beneficiaries (Figure 2) of the unconditional cash program increased from 1.7 million households in 2008/09 to nearly 4 million in 2011/12 and BISP payments (Figure 3) rose from PKR 15.8 billion to PKR 40.5 billion. Each female who has ever been married in the households selected receives PKR 1,000 per month. Originally, the payments were made through the Pakistan Post, but this has now been largely replaced by payments via the BISP ATM card.

Figure 2: Number of BISP beneficiaries receiving cash grants

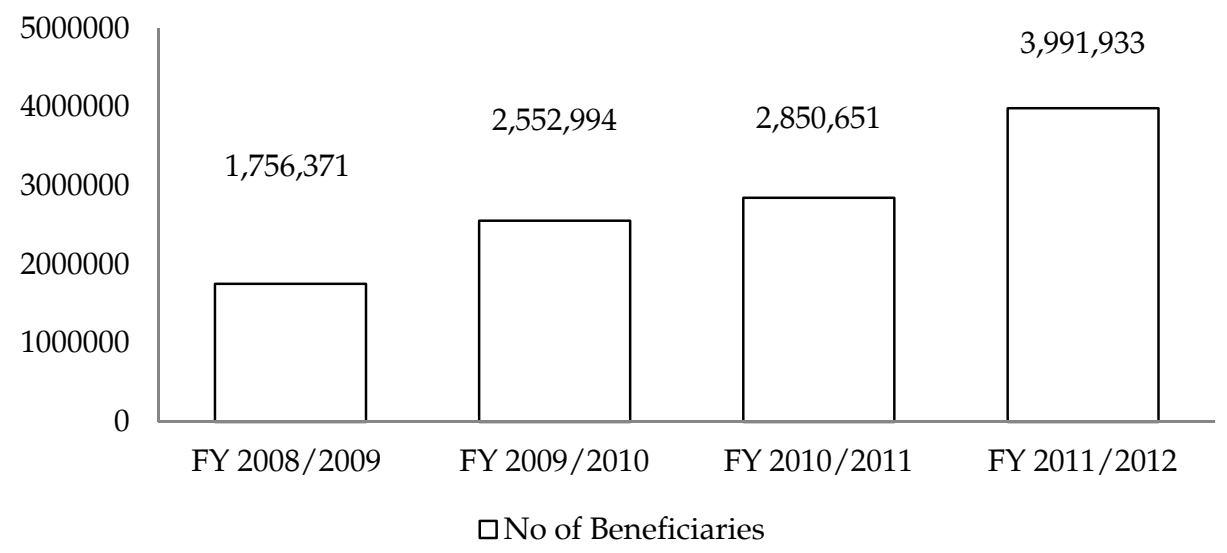

Source: BISP Data

Figure 3: Annual Payment of Cash Grants (in Billion Rs.)

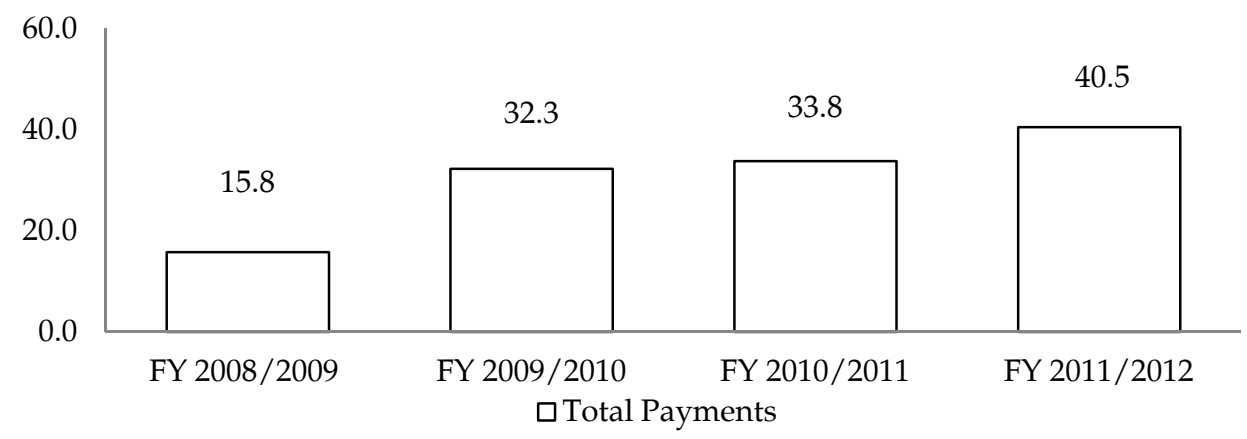

Source: BISP Data 
This period of growth and consolidation is characterized by two phases. In phase I (2008/09 to 2010/11), beneficiaries were identified by parliamentarians; in phase II (2010/11 to 2012/13, as the survey has yet to be completed in two agencies of FATA), a more reliable survey method was used. The Nationwide Poverty Scorecard Survey, the first of its kind in South Asia, enables the BISP to identify eligible households through the application of a proxy means test that determines the welfare status of households on a scale of 0 to 100. The survey, which was started in October 2010 and has been completed across Pakistan (except in two FATA agencies), has the following features.

- It identifies 7.2 million households who are living below a cut-off score of 16.17 .1

- It creates a large and reliable national registry of the socioeconomic status of around 27 million households across Pakistan.

- It uses GPS to map data for the entire country to help make informed decisions (e.g., to respond to natural disasters and other emergencies).

- It validates the targeting process through third-party evaluation.

Figure 4 compares the targeting in phase I (community-based targeting) with that in phase II (poverty scorecard-based targeting), and clearly indicates the rapid expansion in coverage of the BISP. Figure 5 presents province-wise details of the total estimated number of households and the number declared "eligible" for BISP benefits.

Figure 4: Coverage and eligible beneficiaries in phases I and II, and poverty census (millions)

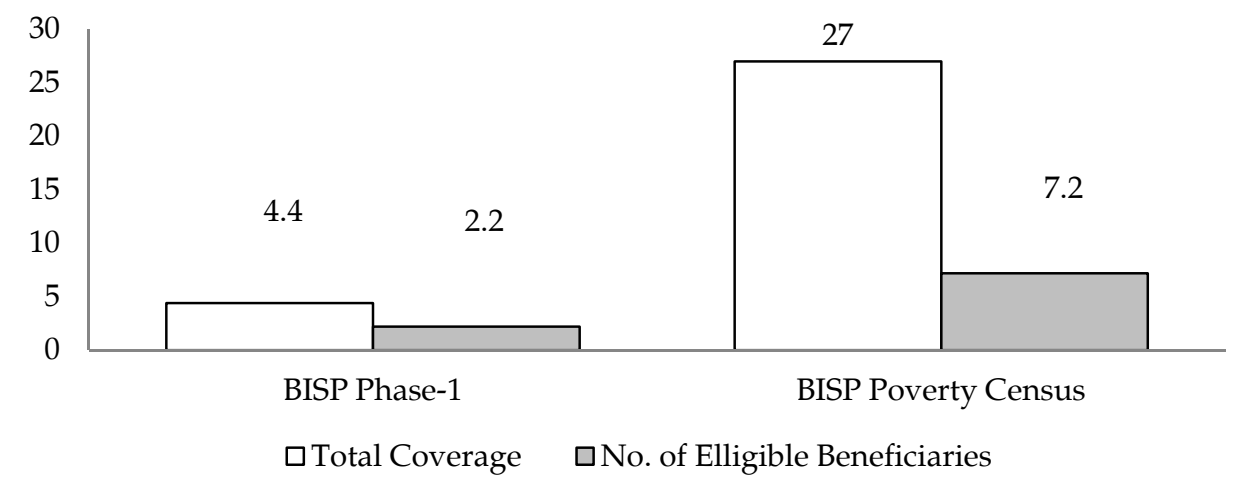

Source: BISP data.

\footnotetext{
${ }^{1}$ A cut-off score of 16.7 does not represent a poverty line, but was decided on the basis of the available fiscal space.
} 
Figure 5: Province-wise aggregates of total BISP eligible households (millions)

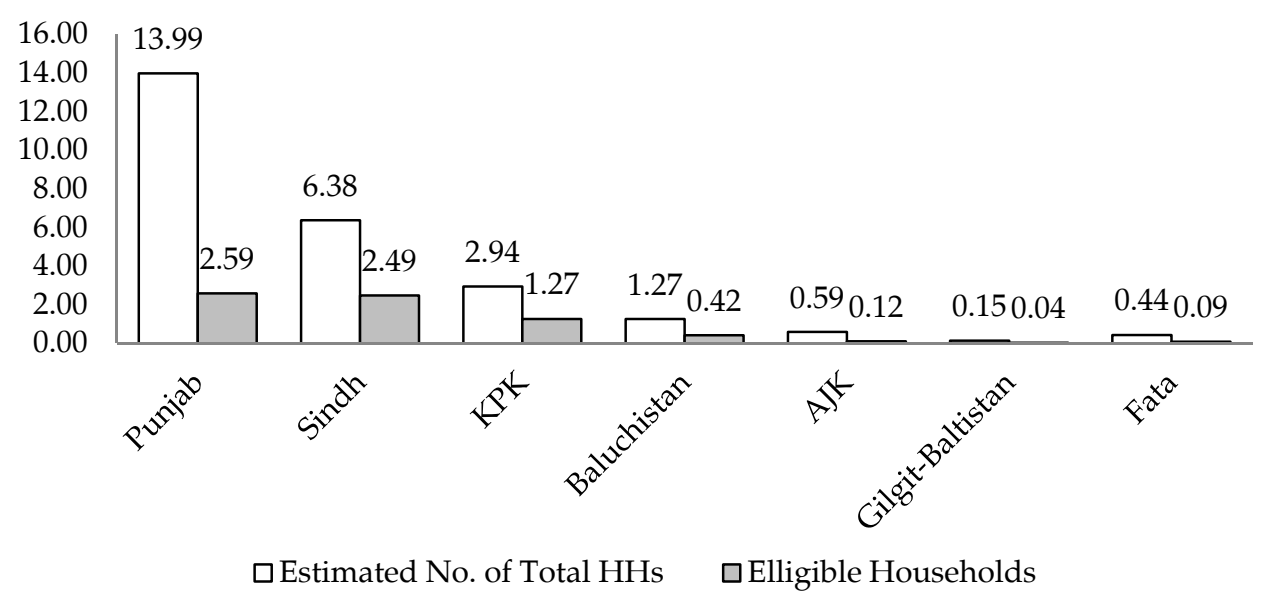

Source: BISP data.

\subsection{Evaluations}

Rigorous evaluations are built into the program's design and are conducted by external organizations to ensure credibility. The evaluations provide invaluable insight into the incentive structure and processes of an intervention and, as such, are an essential part of policy design. Three independent firms were hired to conduct spot-checks of eligible beneficiaries, evaluate the process of program implementation, and carry out a detailed impact evaluation exercise.

The BISP contracted two third parties (Innovative Development Strategies and GHK) to conduct a validation exercise through spot-checks and to evaluate the different procedures relating to the scorecard implementation. The specific objectives of these assignments were to test the completeness and quality of the survey conducted by the partner organizations. The interim findings of both exercises are shared regularly with the BISP. The spot-check assignment found that the overall coverage of the BISP's targeting survey at the national level was 93 percent, and that there was only a small difference in the poverty scores across the two surveys (i.e., the national roll out of the poverty survey and spot-check representative survey). Additionally, the process evaluation interim results showed that almost 85 percent of the stipulated processes were followed for all activities completed under the poverty scorecard survey. 
The program has also been evaluated by the United States Agency for International Development (USAID) under its Budget Support Monitoring initiative. As per its findings, 98.69 percent of beneficiaries received their cash payments: 32 percent via banks through mobile payments, 25 percent through the Pakistan Post, and 41 percent via smartcard. Almost 81 percent spent, on average, a day (or two hours) or PKR 175 to receive the cash grant. This was slightly higher for Balochistan (PKR 200). In 60 percent of the households, senior female members decided how the cash grant was to be used; the rest made joint decisions.

The implementation of cash transfer programs has been accompanied by systematic efforts to measure their effectiveness and understand their broader impact on household behavior. The BISP undertook a baseline study (recently completed by Oxford Policy Management) that is being used as part of a wider impact assessment of the program. The baseline provides data against which to measure the BISP's impact through future surveys, focusing on 11 pre-agreed areas ranging from poverty and consumption expenditure to child nutrition, women's empowerment, and the uptake of education and health services on which BISP could reasonably be expected to have an impact.

The results of the baseline reiterate that the BISP's intended beneficiaries have larger families with a high dependency ratio and low educational attainment, and that are prone to more illnesses than the rest of the population. Children in eligible households are more malnourished than in noneligible households. Overall, the findings were broadly in line with the National Nutrition Survey, with 43 percent of children recorded as stunted, 15 percent as wasted, and 35 percent as underweight. Similarly, the baseline provides details on indicators of household consumption, major shocks, coping mechanisms, and the use of financial services. The study's scope, sampling, and data collection approach will be incorporated in a comprehensive medium-term impact evaluation plan.

The Office of the Auditor General completed a financial audit of the BISP for 2010/11 and 2011/12 in October 2012. The audit report deemed the progress and operations of the program satisfactory and did not highlight any serious problems. The BISP has responded to the audit observations and the audit report will be finalized after a meeting of the Departmental Accounts Committee. The report will be submitted to the BISP's board once finalized. An internal audit is also in process and will be submitted to the board in the near future. 


\subsection{Waseela-e-Taleem (Primary Education Program)}

The BISP has recently launched the co-responsibility cash transfer Waseela-e-Taleem. The program aims to encourage BISP beneficiary families with children aged 5 to 12 years to send their out-of-school children to primary schools (and allow currently enrolled schoolchildren to continue their education) in return for cash transfers with the long-term prospects of human capital formation that would help them move out of abject poverty. This involves a cash transfer of PKR 200 per month paid quarterly (PRs 600 per child) for up to three children in each BISP beneficiary family in return for their compliance with the co-responsibilities of school admissions and a minimum 70 percent quarterly attendance. The BISP intends to implement the program using a phased approach, which involves testing the program in selected districts first and then rolling it out on the basis of learning from the test phase.

The most significant aspect of this initiative is the compliance monitoring of the co-responsibilities by beneficiary families. The coresponsibilities include gaining admission in schools for primary education and maintaining at least 70 percent quarterly attendance. The benefits of noncompliant families/children will be suspended following two consecutive cases of noncompliance with the program's co-responsibilities. The compliance monitoring process is implemented by the district education departments in close coordination with BISP tehsil offices.

The program uses an optical mark recognition-based compliance monitoring process. The quarterly attendance sheets of children from BISP beneficiary families whose school admission has been verified are entered into the BISP's management information system for Waseela-e-Taleem (generated at BISP tehsil offices) and handed over to the education department officer concerned at the tehsil level. Education supervisors from the local education department then collect the attendance sheets for their respective schools and pass them on to the schools, who record the attendance of BISP beneficiary children as per the training provided by BISP's Waseela-e-Taleem training firm. The completed forms are then resubmitted through the same channel they were received.

The program's field operations started on 8 October 2012. The program was officially launched on 9 November 2012. As of 22 January 2013, a total of 21,116 families have enrolled in the program in three districts of Cluster A whose 51,127 children were identified and issued admission verification certificates by enrolment centers under Waseela-e- 
Taleem. The projected annual number of children to be enrolled and the amount of benefits paid is shown in Figures 6 and 7.

An essential component of rigorous program evaluation is built into the design of Waseela-e-Taleem. In order to implement the program as per the procedures laid out in its operational manual and associated guidelines, BISP will hire a firm to carry out operational reviews of the program's implementation through spot-checks and process evaluations. The operational review is important to ensure checks and balances on all the implementing partners of the program and to maximize the outputs by continuously improving the processes on the basis of the feedback received from the operational audit consultancy. Correspondingly a vigorous impact evaluation of Waseela-e-Taleem is also in process.

Figure 6: Projected annual number of children enrolled in Waseela-eTaleem

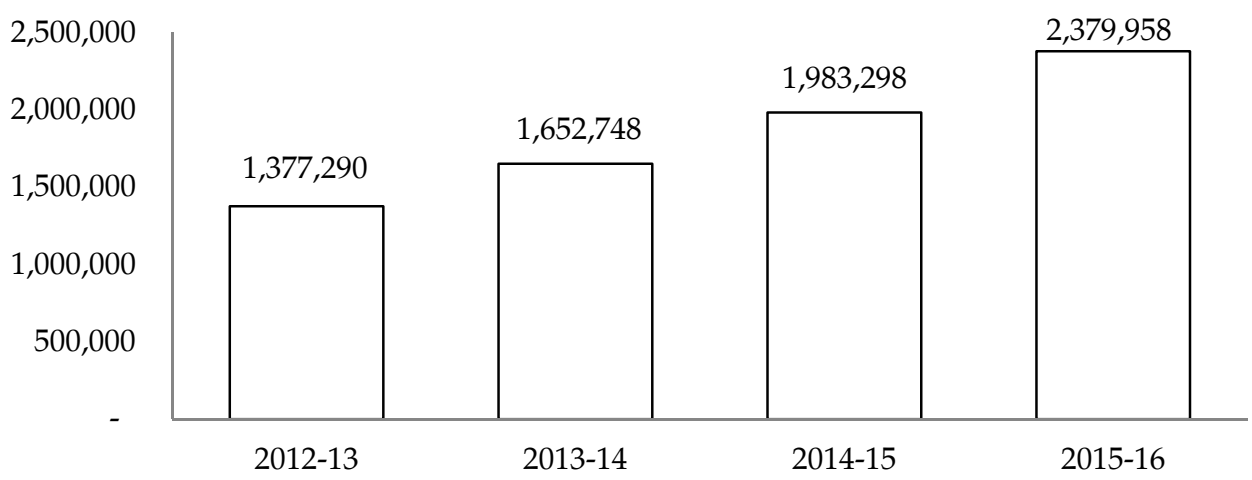

Source: BISP Data

Figure 7: Projected amount of CCT to be paid in Waseela-e-Taleem

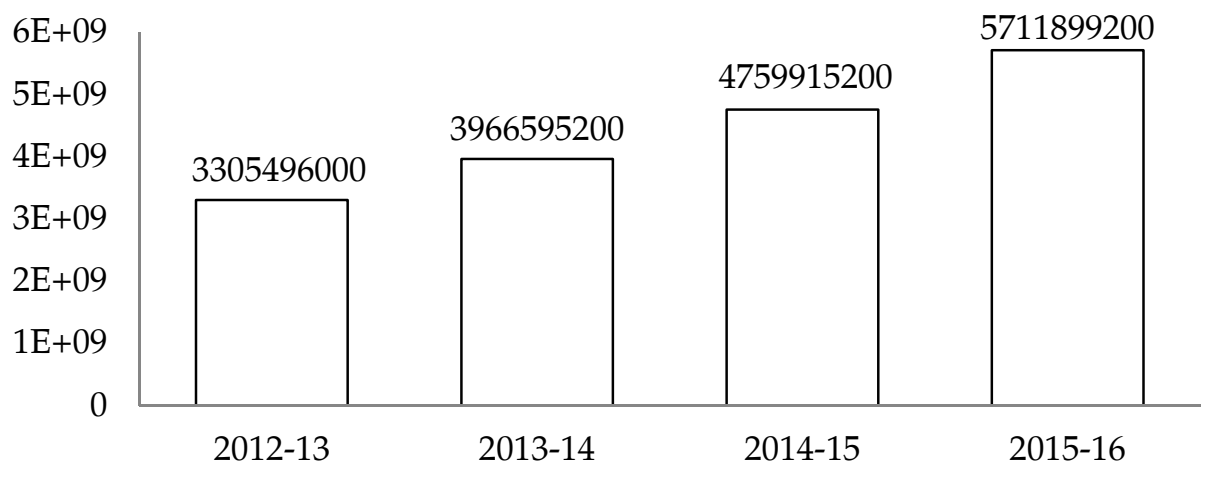

Source: BISP Data 
The baseline will be fielded during March-June 2013, based on a comprehensive quantitative design. Data on impact evaluation, process evaluation, and spot-checks will be collected on a sample basis from program operational offices and beneficiary families, using appropriate data collection tools (such as questionnaires). The data acquired through the operational review will be analyzed critically, using both quantitative and qualitative data analysis techniques. The operational review firm will also ascertain the procedural reasons for errors, if any, by rigorously testing the data. Different thresholds will be defined for error margins and corrective actions suggested by the consultant firm on reaching a threshold. All the relevant stakeholders of the program will be given regular feedback for timely course corrections.

The primary schooling program already meets the core criterion that other such programs struggle with, i.e., it is well targeted by virtue of BISP's well-designed infrastructure. The challenge going forward is to ensure that the demand for education created by this federal program is matched by supply (teachers, teaching material, school buildings); constitutionally, this task rests with the provinces. Aligning the federal and provincial governments' incentives is Pakistan's main challenge as it forges the institutions needed by democracy to deliver development and prosperity.

\subsection{Other Programs}

Complementary interventions play an increasing role in determining the sustainable impact of cash transfer interventions on the uptake of education and health services, nutrition outcomes, and in improving livelihoods to increase households' chances of graduating from poverty. Global experience suggests that, where programs are combined with well-sequenced complementary interventions, they have greater potential. The BISP has also initiated complementary programs including Waseela-e-Rozgar (technical and vocational training), Waseela-e-Haq (microfinance), and Waseela-e-Sehat (life and health insurance). The success of the BISP has encouraged several international donors-the UK Department for International Development (DFID), USAID, the World Bank, and Asian Development Bank-to use its highway to the poor to deliver other much needed services.

\section{PSDF}

The PSDF is an initiative of the Punjab government in collaboration with DFID. It was envisaged as one of the two prongs of the Punjab 
Employment Opportunities Program, the other being livestock development. In the initial phase, the PSDF has been designed to focus on the four poorest districts in southern Punjab (Bahawalpur, Bahawalnagar, Lodhran, and Muzaffargarh). The program addresses poverty, unemployment, and vulnerability by providing skills that help secure jobs or enhance income in self-employment. The livestock program was closed down in mid-2012 because of slow progress, and the funds were transferred to the PSDF with the additional responsibility of providing skills that would improve the quality and size of livestock in the region.

The PSDF is a Section 42 company managed by an independent board of directors (with private sector representation) with a total outlay of GBP 50 million. The program was formally launched in 2011, with the appointment of a CEO. There are 12 board members: seven are nongovernment representatives while four are department secretaries and the CEO. The board has met 13 times since it was set up in October 2010. Its subcommittees are closely involved in giving direction to PSDF operations. The human resource committee has met five times, the audit and finance committee has met six times, and the program design and evaluation committee has met five times since the program's inception.

The PSDF's objective in the four targeted districts is to train 80,000 vulnerable people over five years and restore the credibility of the state in facilitating access to better-paying jobs. The PSDF has launched three principal training schemes: (i) skills for market (training for selfemployment focused on rural areas), (ii) skills for employment (training for employment in small towns/rural areas/the informal sector), and (iii) skills for jobs (training for employment in the formal sector).

The first two categories, offered to the poor and women in rural areas and small towns, are forms of social protection; the third targets educated, unemployed, and vulnerable individuals in urban/peri-urban areas in the four districts. The average duration of the training program for skills for market and skills for jobs is 4 months and 6.5 months, respectively. Trainees receive a stipend of PKR 1,500 per month if the training is within the four districts and PKR 3,000 if located outside. As of June 2013, nearly 30,000 individuals have been trained in 90 different trades, working with 60 public, private, and nongovernment organizations. The program is on course to meet its overall target of training 80,000 trainees in four years. 


\subsection{Program Design}

The PSDF's design represents a major shift in delivering public resources for skills development. It does not provide training itself on premises constructed with its resources and by teachers hired using program fund, nor is it a "captured" fund funneling public money to public sector training institutions insensitive to the market demand for their training programs. Instead, the PSDF identifies the courses to be taught and the trainees to be targeted, and then takes competitive bids from both public and private trainers to provide the training at specified locations. Bids that satisfy the rigorous technical and financial criteria set by the program are then contracted and given the funds to provide the training.

The program design outlined above can work only if the PSDF spends its energy and resources in responding effectively to information flows that match the demand for skills acquired by trainees (that help to find jobs in the market or to improve income in self-employment) with the supply of training programs it funds. Thus, research on household and employer skills needs, gathering market information, fine-tuning courses, setting technical and financial criteria to assess bids, third-party evaluation of training programs, and tracking trainees to assess post-training employment and income status become the core functions of the program.

Given these core functions, the PSDF's success depends on the quality of research that supports its decision-making. Its sponsors have made available adequate technical assistance to procure such research, and the board ensures that a proper balance is kept between the operational needs of delivering the program according to the agreed timeline and the quality of information needed so that the training delivered does indeed match the demand for skills. This design feature allows for ongoing monitoring and evaluation with a feedback loop into program design, and thus facilitates timely course correction.

The PSDF has defined its success in terms of the following bars:

- Select trainees that meet the criteria of vulnerability (people with an income less than USD 2 a day and marginalized women)

- Identify training courses that increase the employability and productivity of trainees

- Promote training by private trainers via competitive bidding by public and private trainers for training contracts 
- Ensure zero-tolerance for "ghost" training programs and training that does not conform to contract specifications

- Assess improvements in the employability and income of trainees who have completed the training program

\subsection{Design Features to Help Meet the Program Bars}

How well the PSDF performs on the bars listed above will be assessed in due course as the program matures and evaluations are completed. This is especially true for the last bar on the program's impact on income. Nonetheless, several design features are already beginning to have an impact on program outcomes.

The evidence-based rollout of the program has used baseline surveys of living conditions in the four districts being targeted. The sample comprises 11,000 households whose skill preferences were surveyed. A survey of employers for skills demanded and a survey of networks for job placement were also conducted. Following these, two categories of skills were identified: (i) skills for market (tailoring, home crafts, etc.) and (ii) skills for jobs (welding, electrical work, cooking, inventory control, etc.). The PSDF therefore has an effective targeting mechanism and a strong system in place to ensure employability and income generation.

\subsection{Vulnerability}

The program's focus on four districts in southern Punjab (Bahawalpur, Bahawalnagar, Lodhran, and Muzaffargarh)—the least developed in terms of poverty, education, and health indicators-allows it to meet the first bar. The selection of trainees satisfies the criterion of vulnerability in that their incomes are less than USD 2 a day. Nearly 40 percent of the beneficiaries are women.

\subsection{Course-Correcting Design Features}

Household surveys conducted in the early stages of the program revealed a high degree of enthusiasm for training among households, even among young women in these relatively conservative districts. This was followed by a series of randomized control trials (RCTs) to assess whether this enthusiasm could be sustained in terms of committing household time to the training program. The trial involved distributing vouchers to households with potential trainees that could be cashed when the training was undertaken. 
The results were discouraging. The voucher uptake corresponded to an abysmal 5 percent of the general population and was even lower among the targeted population (those that met the criterion of vulnerability). Further analysis showed that the low uptake was not due to a lack of demand for training but rather due to program design factors such as inadequate information on training programs, distance from the training center, the limited number of courses offered, and low stipends. The voucher uptake was even lower for women due to factors such as the number of household dependents, both the elderly and children.

The PSDF's program design was adjusted in light of the RCT findings. The new round of bids for courses offered to women trainees whose uptake was very low, were adjusted by providing them with more information on the program, specifying the location of training centers to address the distance concern, and offering more varied courses.

The results of these adjustments can be seen in Figures 8 and 9. By adjusting distance and providing more village-based training, the voucher uptake more than doubled. Offering more varied courses also met with resounding success in increasing women's voucher uptake (Figure 9). Moreover, none of these measures involved increasing the stipend. These experiments have helped fine-tune the program in terms of training location, modes of trainee mobilization, and courses offered.

\section{Figure 8: Impact of village-based training: Overall voucher uptake by} training (percentage of female participation)

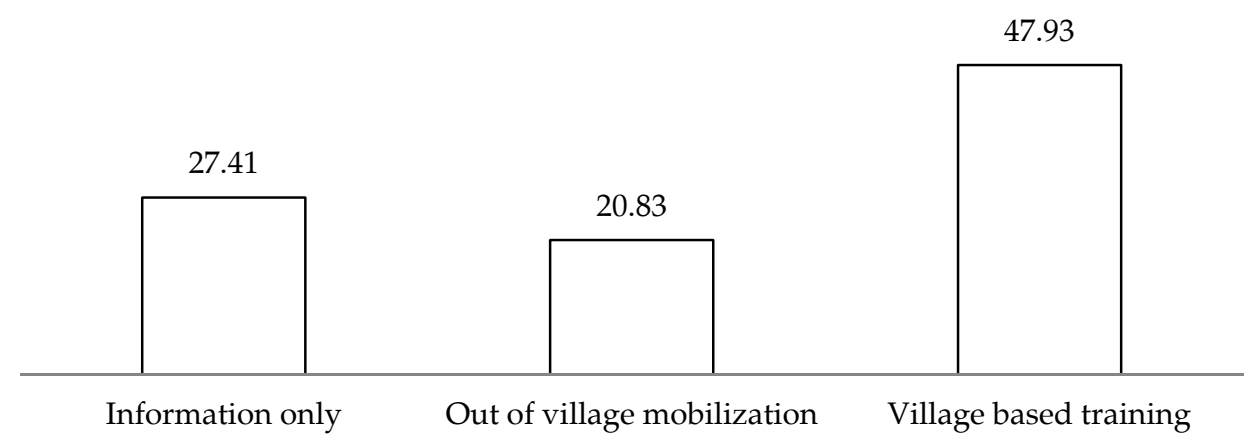

Source: BISP Data 
Figure 9: Course desirability matters: Voucher uptake in village-based training by course

(percentage of female participation)

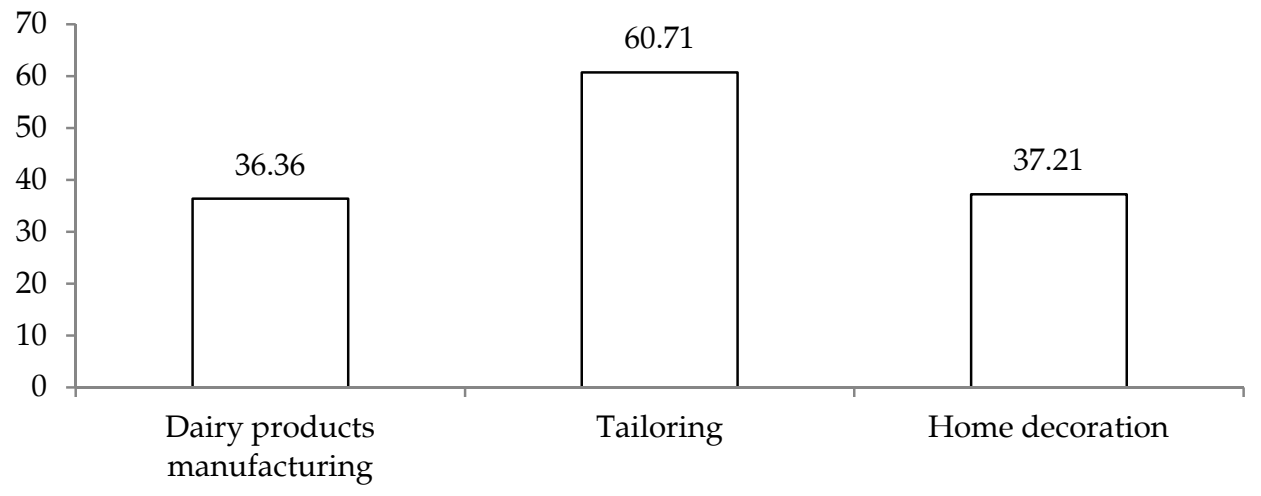

Source: BISP Data

\subsection{Private Sector Development}

The PSDF's strategy to develop private sector trainers seeks to create competition in the market for better results. The private sector is invited to bid for all three main categories of training programs, i.e., skills for market, for jobs, and for employment. Figure 10 shows that, after NGOs, it is the private sector that secures the most contracts in all three categories of training. This creates entrepreneurship in training that was, until recently, dominated by public sector training institutions. It also demonstrates that the potential for growth, as seen in low-cost private formal education in recent decades, is substantial.

\section{Figure 10: Private sector development (mix of providers)}

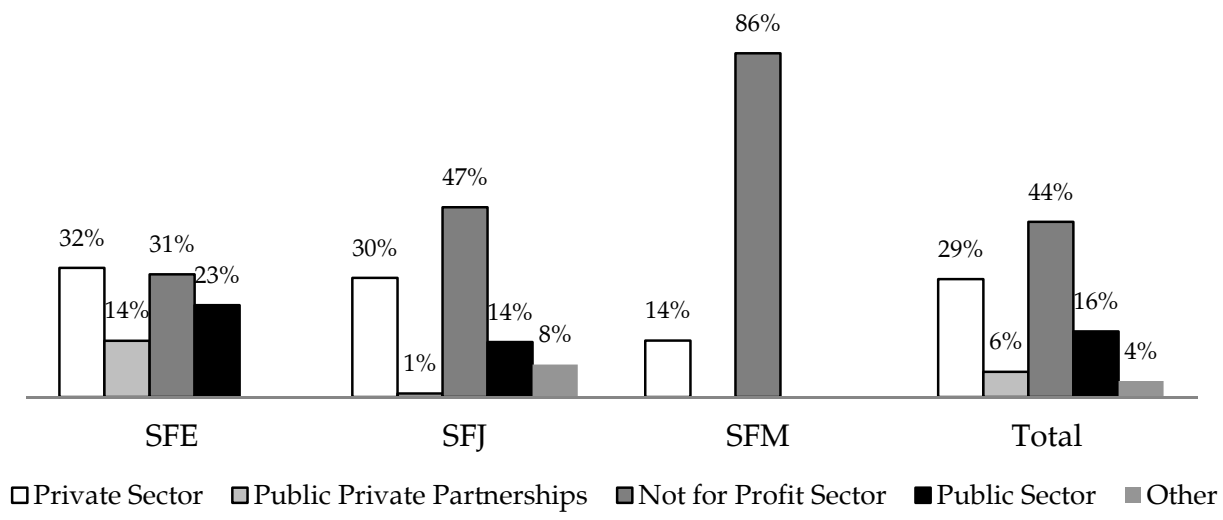

Source: BISP Data 


\subsection{Third-Party Monitoring and Cost-Effectiveness}

A robust third-party monitoring system has been put in place to ensure the availability of inputs-trainers, learning materials, and trainee attendance. The program has zero-tolerance for corruption: all bids are transparent and there are heavy checks in place to ensure that no ghost programs are funded by the PSDF; this entails ongoing third-party monitoring and independent yearly financial audits. Testing services that ensure the quality of the training programs are outsourced to national and international accredited certifying agencies.

The program's cost-effectiveness relative to the Sindh Skills Development Project is illustrated in Figure 11.

Figure 11: PSDF cost-effectiveness: Comparison with four skills development programs

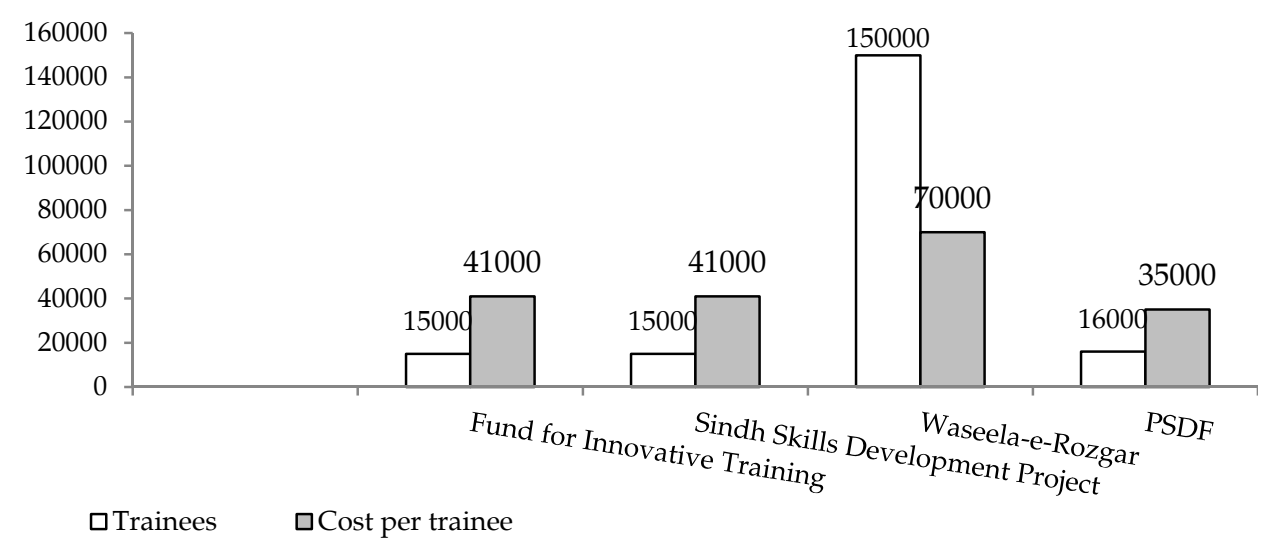

Source: BISP Data

\section{Concluding Remarks: Social Protection Going Forward}

\subsection{BISP}

The BISP was put through a crucial sustainability test in the May 2013 election that resulted in the PPP's defeat and brought the PML-N, the main opposition party, into power with a comfortable majority in Parliament. It was feared during the transition that the PML-N might jettison the program as it is too closely identified with the PPP. These concerns have now been adequately addressed. The 2013/14 budget presented to the newly elected Parliament by the PML-N government shows its commitment to continuing the program. Indeed, the cash transfer 
in the core BISP subprogram has been increased to PKR 1,200 per month (from the previous PKR 1,000). Furthermore, after some debate, the government has decided to retain the program's original name, indicating the maturity of the political process in Pakistan.

Having satisfied ourselves that the BISP is technically sound, the other questions to ask are whether the program is ethically desirable and financial feasible. One ethical concern that arises is whether the program discourages enterprise by people and creates a permanent pool of people dependent on government handouts. Responding to this concern, the BISP has developed an exit strategy in the form of its Waseela-e-Rozgar (skills development) and Waseela-e-Haq (entrepreneurship development) programs. These programs are still in their early stages, and need to be evaluated before scaling them up as a full-blown exit strategy.

The size of the BISP subprograms is expected to triple by 2015/16 (Figure 12). Their total expense, as of 2011/12, was PKR 43 billion in addition to PKR 6 billion in administrative costs (including liaison with NADRA, banks, and the Pakistan Post).

Figure 12: Size of BISP subprograms
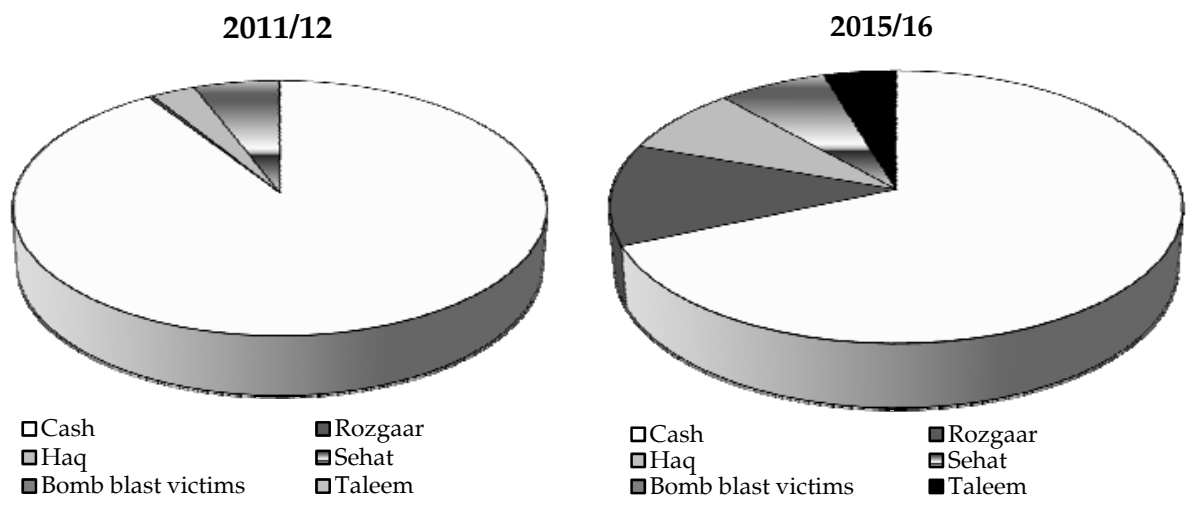

Source: BISP Data

The program's financial viability is inevitably a source of worry for a fiscally strapped economy. At PKR 60 billion per annum and growing, it is a large financial commitment by a government already facing stagnant revenues. However, it is worth bearing in mind that a large part of the annual energy subsidy of PKR 500 billion supports the consumption of middle-class residential homes, as do the huge subsidies given to the lossmaking railways and Pakistan International Airlines. Furthermore, in the 
last four years, the tax expenditure (which is a kind of subsidy) enjoyed by middle-class income taxpayers who should be in the tax net but are not, is estimated by the Federal Board of Revenue to be the size of Pakistan's annual defense expenditure. The BISP's PKR 60 billion for the poor is modest by comparison.

Clearly, there is room for improvement in all such large and complex programs as the BISP. Some of the issues going forward include the need to (i) continually update the program's database and list of beneficiaries; (ii) enhance the different subprograms' capacity, particularly with regard to several other programs that have recently been launched; and (iii) develop good working arrangements with the provinces following the $18^{\text {th }}$ Amendment. Also, fiscal prudence requires that some trades be made with subsidized programs for the middle class to make space for the BISP. Democratically elected governments have to make sure that the poor do not always come out the worst in all such trades.

\subsection{PSDF}

Encouraged by the promising PSDF roll out, plans are underway to expand its operations to all of Punjab. The number of trainees is to be increased from the current target of 20,000 per annum to 500,000 trainees per annum by 2020 - a huge multiple of 25 (see Table 2).

This has important implications for program design. First, employers located in the relatively more prosperous districts of Punjab will become important stakeholders and catering to their training needs will imply a substantial increase in and predominance of training courses aimed at skills for jobs. Second, the PSDF will increasingly become a program focused on economic growth as the share of training for skills for the market-and with that the program's social protection dimensiondeclines in importance. Third, the PSDF will need to be vigilant in ensuring that the social protection dimension of skills training, especially in the poorer districts, continues to receive the management's attention. Fourth, private sector trainers will be challenged to respond to the considerably larger training cohort requiring increasingly complex training courses. Finally, the capacity of the PSDF itself will need to be built up rapidly to manage the much larger program. 
Table 2: Targeted number of trainees

\begin{tabular}{lccc}
\hline & & \multicolumn{2}{c}{ Target under expansion strategy } \\
\cline { 3 - 4 } Year & Pilot districts & $\begin{array}{c}\text { Punjab } \\
\text { (excl. pilot districts) }\end{array}$ & $\begin{array}{c}\text { Total target: } \\
\text { Number of trainees }\end{array}$ \\
\hline $2011 / 12$ & 10,000 & Preparation & 10,000 \\
$2012 / 13$ & 30,000 & 10,000 & 40,000 \\
$2013 / 14$ & 35,000 & 100,000 & 135,000 \\
$2014 / 15$ & 5,000 & 200,000 & 205,000 \\
$2015 / 16$ & - & 280,000 & 280,000 \\
$2016 / 17$ & - & 350,000 & 350,000 \\
$2017 / 18$ & - & 410,000 & 410,000 \\
$2018 / 19$ & - & 460,000 & 460,000 \\
$2019 / 20$ & - & 500,000 & 500,000 \\
\hline
\end{tabular}

Source: Punjab Skills Development Fund.

Another set of challenges is associated with the fiscal sustainability of the envisaged, much larger program. Given low overall government revenues, the subsidy built into its current design will no longer be feasible. Public-private partnerships and asking trainees to pick up a larger share of the training cost would be one solution. The earlier stages of the PSDF rollout will have demonstrated the increase in worker productivity associated with training and the ensuing increase in employers' profits and higher wages for trained workers. This will create incentives for both employers and workers to pick up a greater share of the cost of training. In turn, it will pave the way for the government to change its role from funding training to providing regulatory oversight (setting standards, ensuring quality, checking fraud, etc.) and facilitating knowledge exchange (on emerging skills needs) between training seekers (employers and workers) and private training providers. 


\section{References}

Gazdar, H. (2011). Social protection in Pakistan: In the midst of a paradigm shift? Economic and Political Weekly, July 9.

Shaikh, H. (2013). The Islamic Republic of Pakistan: Updating and improving the social protection index. Report prepared for the Asian Development Bank, Islamabad, Pakistan.

Pakistan, Ministry of Finance. (2011). Poverty reduction strategy paper II: Progress report 2010-11. Islamabad, Pakistan: Author. 
Annex

Table A1: Poverty line estimates, 2005-12

\begin{tabular}{lc}
\hline Year & Poverty line (PRs) \\
\hline $2005 / 06$ & 948.93 \\
$2006 / 07$ & $1,046.48$ \\
$2007 / 08$ & $1,231.18$ \\
$2008 / 09$ & $1,522.97$ \\
$2009 / 10$ & $1,712.88$ \\
$2010 / 11$ & $2,020.35$ \\
$2011 / 12$ & $2,243.19$ \\
\hline
\end{tabular}

Source: Economic Survey of Pakistan, 2010.

Table A2: Poverty headcount rates by urban-rural divide (\%)

\begin{tabular}{lcccc}
\hline & $\mathbf{1 9 9 8 / 9 9}$ & $\mathbf{2 0 0 0 / 0 1}$ & $\mathbf{2 0 0 4 / 0 5}$ & $\mathbf{2 0 0 5 / 0 6}$ \\
\hline National & 31.1 & 34.5 & 23.9 & 22.3 \\
Urban & 21.4 & 22.7 & 14.9 & 13.1 \\
Rural & 35.1 & 39.3 & 28.1 & 27.0 \\
Punjab & & & & \\
Urban & 23.9 & 23.4 & 16.8 & 12.1 \\
Rural & 33.0 & 34.8 & 28.4 & 21.0 \\
Sindh & & & & \\
Urban & 14.9 & 20.3 & 10.8 & 11.5 \\
Rural & 34.3 & 48.0 & 22.7 & 31.0 \\
Balochistan & & & & \\
Urban & 24.5 & 27.3 & 17.9 & 32.4 \\
Rural & 21.1 & 39.0 & 28.7 & 56.6 \\
KP & & & & \\
Urban & 26.1 & 30.4 & 22.1 & 23.6 \\
Rural & 21.1 & 39.0 & 28.7 & 56.6 \\
\hline
\end{tabular}

Source: Planning Commission of Pakistan. All poverty headcount rates are official estimates. 